\title{
Dyssynchrony as a marker of adverse prognosis among patients with coronary artery disease and heart failure
}

\author{
Saurabh Malhotra, MD, MPH, FASNC ${ }^{\mathrm{a}, \mathrm{b}}$ \\ a Cook County Health, Chicago, IL \\ b Rush Medical College, Chicago, IL
}

Received Oct 20, 2019; accepted Oct 21, 2019

doi: $10.1007 / \mathrm{s} 12350-019-01945-\mathrm{z}$

\section{See related article, pp. 1622-1632}

Left ventricular dyssynchrony (LVD) is referred to disorganized ventricular contractility and has been extensively studied among patient with heart failure (HF) and low left ventricular ejection fraction (EF). While some degree of disorganized contractility exists in normal ventricles, presence of LVD is defined by limits not seen in normal patients. While most reports have focused on the assessment of systolic LVD and its diagnostic and prognostic attributes among patients with heart failure, there are emerging data on the value of assessing diastolic LVD by phase analysis of gated single photon emission tomography (GSPECT). ${ }^{1-3}$ Simply put, while phase analysis of gated SPECT determines the time (phase) of onset of myocardial contraction for calculation of systolic phase indices, the time of onset of mechanical relaxation is used for calculation of diastolic phase indices. ${ }^{2}$ Similar to systolic LVD, phase standard deviation (PSD) and phase histogram bandwidth (HBW) are used as indices to describe the presence and severity of diastolic LVD.

In this issue of the Journal of Nuclear Cardiology, Fudim et al. report both systolic and diastolic indices of LVD as predictors of mortality among patients with CAD and $\mathrm{HF}^{4}{ }^{4}$ The authors conducted a retrospective study of patients who underwent a GSPECT between 2003 and 2009, and who also had at least 50\% stenosis

Reprint requests: Saurabh Malhotra, MD, MPH, FASNC, Cook County Health, Chicago, IL; drsmalhotra@hotmail.com and saurabh.malhotra@cookcountyhhs.org

J Nucl Cardiol 2020;27:1633-6.

$1071-3581 / \$ 34.00$

Copyright (C) 2019 American Society of Nuclear Cardiology. in one major epicardial vessel. Data on 1294 patients were evaluated of whom a quarter had a history of HF, as clinically determined by their respective physicians and providers. Both systolic and diastolic LVD parameters were assessed by phase analysis of GSPECT, with the application of the following LVD cut-offs, derived from a control population: systolic PSD $=46.9^{\circ}$, systolic $\mathrm{HBW}=134^{\circ}$, diastolic $\mathrm{PSD}=51.3^{\circ}$, and diastolic HBW $=155.8^{\circ}$. Patients with CAD and HF had a greater prevalence of both systolic (up to $31 \%$ vs up to $15 \%$ ) and diastolic LVD (up to $29 \%$ vs up to $15 \%$ ), when compared to those with $\mathrm{CAD}$ alone. Over a median follow-up of 6.7 years, there were 537 deaths, and as expected, patients with CAD and HF had a worse survival than those with CAD alone. History of HF and LVD indices (both systolic and diastolic) were independent predictors of all-cause mortality and cardiovascular mortality, after adjusting for clinically significant variables. The prognostic value of systolic and diastolic indices of LVD for all-cause and cardiovascular mortality did not significantly differ by the presence of HF among these patients with CAD.

This report is an extension of a previously published observational analysis from the same cohort. ${ }^{5}$ Previously, the authors have shown diastolic LVD to be of incremental prognostic value above clinically significant variables and systolic LVD. They now extend the results from their clinical database by performing a subgroup analysis among patient with and without a history of HF. The current report adds to the growing literature on the prognostic value of LVD, specifically that of diastolic LVD. ${ }^{5}$ In addition to the prior studies reporting an association of LVD with cause-specific outcomes, ${ }^{6,7}$ this study further expands the prognostic value of LVD to predict all-cause mortality. Especially intriguing is the prediction of outcomes by LVD regardless of a history of HF. Although the prevalence of LVD was greater among those with HF, HF did not influence the 
association between LVD and mortality. There could be several explanations for the lack of interaction between $\mathrm{HF}$ and LVD for predicting mortality. First, it is possible that outcomes in these patients with known epicardial CAD were largely be driven by the presence of ischemia. Phase analysis of post-stress gated $\mathrm{SPECT}^{8}$ and $\mathrm{PET}^{9,10}$ myocardial perfusion imaging has shown an association between LVD with ischemia and abnormal myocardial blood flow. Improvement in LVD indices on serial gated SPECT has also been reported following revascularization ${ }^{11}$ and medical therapy. ${ }^{3}$ Further analysis of the present data by accounting for the presence of ischemia and its global burden would have most certainly shed more light on the interaction of ischemia with LVD in predicting mortality and possibly explain as to why HF did not influence this relationship. Secondly, as opined by the authors themselves, it is possible that the outcomes in these patients with CAD could also be driven by the presence of microvessel disease which cannot be assessed by conventional gated SPECT studies. This could be especially true for those with LVD in the presence of anatomical CAD, but with normal perfusion and a normal left ventricular EF. In these patients, LVD could be an indicator of subclinical ischemic cardiomyopathy and could provide risk prediction similar to that conferred by abnormal myocardial blood flow on PET in patients with a normal relative perfusion.

The lack of influence of HF on the association between LVD and mortality could also be a result of a relatively low prevalence of LVD in this population. Among patients with HF, the highest prevalence of LVD was about $30 \%$. Although it is likely that this prevalence would be higher among those with $\mathrm{EF}<50 \%$, these data were not provided by the authors. A $30 \%$ prevalence, though twice that of those with no HF, is substantially lower than $50-75 \%$ reported by prior studies in patients with HF. ${ }^{6}$ Although the prevalence of LVD in the prior studies was likely influenced by more severely reduced $\mathrm{EF}$, it does suggest that the lack of an impact of HF over LVD's ability to predict mortality could be due to a relatively 'healthy' population studied by Fudim et al. ${ }^{4}$ Lastly, the low prevalence of LVD among HF patients in this study could be explained by how LVD was defined. As noted by the authors, their cut-offs of LVD were derived from a cohort of 103 normal patients whose gated SPECT studies were evaluated for LVD by a phase analysis program specific to Emory Cardiac Toolbox (ECTb, Syntermed Inc. Atlanta, GA). The methodology and demographics of these 'normal' controls have not been described, though the phase indices seemed to have been derived from the latest iteration ${ }^{5}$ of the same software used by Chen et al. in their seminal work on phase analysis. ${ }^{12}$ While there are expected differences in phase analysis indices when GSPECT data are reconstructed by different software, ${ }^{13,14}$ the normal cut-off used by Fudim et al. ${ }^{4}$ are strikingly higher than those reported previously in similarly large derivation cohorts. ${ }^{15}$ These values are significantly higher than reported from the same software (likely older version) by Chen et al. (initial work on LVD) ${ }^{12}$ and by Romero-Farina et al., ${ }^{15}$ among normal controls. If this severe variability in measures of phase analysis is solely due to change in SPECT software versions need further investigation, as this will significantly hamper application and serial assessment of LVD in at-risk patients. It is intuitive that more conservative estimates

Table 1. Reported upper limits of phase parameters from normal controls

\begin{tabular}{|c|c|c|c|c|c|}
\hline Author & Software & $\begin{array}{c}\text { Population } \\
\text { (n) }\end{array}$ & $\begin{array}{c}\text { PSD } \\
\text { (in degrees) }\end{array}$ & $\begin{array}{c}\text { HBW } \\
\text { (in degrees) }\end{array}$ & $\begin{array}{c}\text { Dyssynchrony } \\
\text { Type }\end{array}$ \\
\hline Trimble et al. ${ }^{17}$ & ECTb & 50; USA & 14.4 & 45.7 & Systolic \\
\hline Chen et al. ${ }^{12}$ & ECTb & 90; USA & $\begin{array}{l}\text { Men }=24.4 \\
\text { Women=22.2 }\end{array}$ & $\begin{array}{l}\text { Men }=62.3 \\
\text { Women }=49.8\end{array}$ & Systolic \\
\hline Chen et al. ${ }^{2}$ & ECTb & 30; USA & $\begin{array}{l}11.7 \\
18.3\end{array}$ & $\begin{array}{l}40.2 \\
53.1\end{array}$ & $\begin{array}{l}\text { Systolic } \\
\text { Diastolic }\end{array}$ \\
\hline Romero-Farina et al. ${ }^{15}$ & ECTb & 150; Spain & 22 & 60.5 & Systolic \\
\hline Nakajima et al. ${ }^{13}$ & $\begin{array}{l}\text { ECTb } \\
\text { QGS } \\
\text { HFV } \\
\text { CREPO }\end{array}$ & 69; Japan & $\begin{array}{l}23 \\
11 \\
10 \\
17\end{array}$ & $\begin{array}{l}49 \\
39 \\
38 \\
64\end{array}$ & Systolic \\
\hline Fudim et al. ${ }^{4}$ & $\mathrm{ECTb}$ & 103; USA & $\begin{array}{l}52 \\
47\end{array}$ & $\begin{array}{l}135 \\
156\end{array}$ & $\begin{array}{l}\text { Systolic } \\
\text { Diastolic }\end{array}$ \\
\hline
\end{tabular}

PSD phase standard deviation, HBW histogram bandwidth, ECTb Emory Cardiac Toolbox, QGS quantitative gated SPECT, $H F V$ heart function view, $c R E P O$ cardio REPO 
of LVD are likely going to underestimate its prevalence and could dilute the influence of HF over the relationship between LVD and mortality. Reported normal dyssynchrony cut-offs from different studies are shown in Table 1.

While the current report by Fudim et al. is constrained by demographic, clinical, and methodological issues, it does underscore the prognostic value of LVD among patients with CAD. This brings up an important question - should assessment of LVD be routinely performed for patients undergoing GSPECT? Some proponents of LVD have suggested that a normal MPI should be reported only when LVD is also normal in addition to perfusion, thickening, and function. ${ }^{16}$ While this may be reasonable in a population without HF, as LVD may provide additive value, its application from a prognostic standpoint alone among those with $\mathrm{CAD}$ and HF needs careful consideration. In these patients is LVD a result of ischemia or stunning from CAD or driven by HF? While the presence of LVD may guide therapeutic management, such as revascularization for CAD or resynchronization therapy in HF, prognostication itself may not be of significant clinical relevance in all comers. However, this could be of particular value among those with suspected CAD with an otherwise normal MPI, wherein the presence of LVD could be an indicator of significant ischemic heart disease (epicardial or microvessel) and thus could guide further management. Despite the growing data supporting the prognostic value of LVD, its routine application to guide management is likely not ready for primetime. This is constrained by variability in measurement of LVD (typified by the analysis in this paper), heterogeneity in studied populations, and the heterogeneity of outcomes. From a therapeutic standpoint, should application abnormal LVD results in patients with normal perfusion and function on GSPECT be akin to that of strain imaging on echocardiography? Speckle tracking strain echocardiography has been around for over a decade now, but really has not penetrated clinical practice barring specific clinical situations. Although assessment of myocardial strain assessment is slowly becoming standard of care in oncology patients, medical therapy for 'subclinical' cardiomyopathy, identified by abnormal strain in the setting of normal EF, is still not routinely informed by the results of speckle tracing echocardiography. The repeatability of phase analysis, in carefully selected patients, may allow for identification of abnormal alterations in myocardial contractility when EF is still preserved. This diagnosis of 'subclinical' cardiomyopathy coupled with the published prognostic value of LVD among patients with normal EF could potentially guide early institution of medical therapy for HF.

\section{Disclosures}

Speaker's Bureau-Pfizer Inc. Advisory Board-Akcea Therapeutics.

\section{References}

1. Alexanderson-Rosas E, Espinola-Zavaleta N, Garcia EV, et al. Diastolic dyssynchrony assessment by gated myocardial perfusion-SPECT in subjects who underwent cardiac resynchronization therapy. J Nucl Cardiol 2019. https://doi.org/10.1007/s12350-01901845-2.

2. Chen J, Kalogeropoulos AP, Verdes L, Butler J, Garcia EV. Leftventricular systolic and diastolic dyssynchrony as assessed by multi-harmonic phase analysis of gated SPECT myocardial perfusion imaging in patients with end-stage renal disease and normal LVEF. J Nucl Cardiol 2011;18(2):299-308.

3. Venkataraman R, Chen J, Garcia EV, et al. Effect of ranolazine on left ventricular dyssynchrony in patients with coronary artery disease. Am J Cardiol 2012;110(10):1440-5.

4. Fudim M, Ftahallah M, Shaw L, et al. The prognostic value of diastolic and systolic mechanical left ventricular dyssynchrony among patients with coronary artery disease and heart failure. $\mathbf{J}$ Nucl Cardiol 2019;12:1215-26.

5. Fudim M, Fathallah M, Shaw LK, et al. The prognostic value of diastolic and systolic mechanical left ventricular dyssynchrony among patients with coronary heart disease. JACC Cardiovasc Imaging 2019;12(7 Pt 1):1215-26.

6. Malhotra S, Pasupula DK, Sharma RK, Saba S, Soman P. Relationship between left ventricular dyssynchrony and scar burden in the genesis of ventricular tachyarrhythmia. J Nucl Cardiol 2018;25(2):555-69.

7. Aljaroudi WA, Hage FG, Hermann D, et al. Relation of leftventricular dyssynchrony by phase analysis of gated SPECT images and cardiovascular events in patients with implantable cardiac defibrillators. J Nucl Cardiol 2010;17(3):398404.

8. Chen CC, Shen TY, Chang MC, et al. Stress-induced myocardial ischemia is associated with early post-stress left ventricular mechanical dyssynchrony as assessed by phase analysis of 201T1 gated SPECT myocardial perfusion imaging. Eur J Nucl Med Mol Imaging 2012;39(12):1904-9.

9. Van Tosh A, Votaw JR, Cooke CD, Reichek N, Palestro CJ, Nichols KJ. Relationships between left ventricular asynchrony and myocardial blood flow. J Nucl Cardiol 2017;24(1):43-52.

10. Malhotra S, Canty JM Jr. Vasodilator stress and left ventricular asynchrony. J Nucl Cardiol 2017;24(1):53-6.

11. Malhotra S, Pasupula D, Sharma R, Khanna M, Soman P. Relationship between myocardial ischemia and left ventricular dyssynchrony on serial SPECT. J Nucl Cardiol 2013;20(4):672.

12. Chen J, Garcia EV, Folks RD, et al. Onset of left ventricular mechanical contraction as determined by phase analysis of ECGgated myocardial perfusion SPECT imaging: Development of a diagnostic tool for assessment of cardiac mechanical dyssynchrony. J Nucl Cardiol 2005;12(6):687-95.

13. Nakajima K, Okuda K, Matsuo S, Kiso K, Kinuya S, Garcia EV. Comparison of phase dyssynchrony analysis using gated myocardial perfusion imaging with four software programs: Based on the Japanese Society of Nuclear Medicine working group normal database. J Nucl Cardiol 2017;24(2):611-21. 
14. Malhotra S, Soman P. Software-dependent processing variability in SPECT functional parameters: Clinical implications. J Nucl Cardiol 2017;24(2):622-4.

15. Romero-Farina G, Aguade-Bruix S, Candell-Riera J, Pizzi MN, Garcia-Dorado D. Cut-off values of myocardial perfusion gatedSPECT phase analysis parameters of normal subjects, and conduction and mechanical cardiac diseases. J Nucl Cardiol 2015;22(6):1247-58.

16. Romero-Farina G, Aguade-Bruix S. Perspective and future direction of intraventricular mechanical dyssynchrony assessment. J Nucl Cardiol 2019. https://doi.org/10.1007/s12350-019-01604-3.
17. Trimble MA, Velazquez EJ, Adams GL, et al. Repeatability and reproducibility of phase analysis of gated single-photon emission computed tomography myocardial perfusion imaging used to quantify cardiac dyssynchrony. Nucl Med Commun 2008;29(4):374-81.

Publisher's Note Springer Nature remains neutral with regard to jurisdictional claims in published maps and institutional affiliations. 